\title{
EFEKTIFITAS STRATEGI KOMUNIKASI POLITIK ELIT MUHAMMADIYAH DIY DALAM PEMENANGAN PEMILU DPD-RI TAHUN 2014
}

\author{
Anang Masduki, Rendra Widyatama \\ Universitas Ahmad Dahlan Yogyakarta \\ anang_masduki@yahoo.com,rendrawidyatama@yahoo.com
}

\begin{abstract}
ABSTRAK
Muhammadiyah telah menempatkan anggotanya menjadi wakil di DPD-RI sejak tahun 2004. Pada pemilu tahun 2014, Muhammadiyah DIY kembali mengajukan kadernya sebagai wakil anggota DPD-RI, namun jumlah suara yang diperoleh cenderung turun. Keadaan tersebut membuat elit Muhammadiyah di tingkat PWM DIY perlu menyusun strategi agar tidak lagi terjadi penurunan suara. Dari hasil penelitian pertama, diperoleh beberapa kesimpulan; Pertama, di DIY terdapat persaingan identitas yaitu identitas budaya keraton, ormas Muhammadiyah, NU, dan non muslim, nasionalis, dan abangan. Kedua, terjadi maksimalisasi alat peraga. Ketiga, Muhammadiyah menonjolkan identitas budaya penggunaan peci, dan menggunakan tagline: muda dan cerdas, gesang prasojo, makaryo kagem Ngayogyokarto. Keempat, Muhammadiyah melakukan gerakan melalui pendekatan kultural dan structural, misalnya dengan mengirim sms ke seluruh pimpinan Muhammadiyah se DIY dan warga Muhammadiyah yang bekerja di amal usaha Muhammadiyah. Olehkarenanya, penelitian tersebut memerlukan kesinambungan untuk menganalis efektifitas setrategi komunikasi politik yang dilakukan elit Muhammadiyah DIY memenangkan kader Muhammadiyah saat mengajukan M. Afnan Hadikusumo dalam pemilihan anggota DPD-RI tahun 2014. Tujuan penelitian ini adalah merumuskan strategi komuniikasi politik yang lebih baik dalam konteks pemilihan anggota DPD di masa mendatang, mengingat pemilu-pemilu yang akan datang lebih kompetitif.
\end{abstract}

Penelitian ini akan dilakukan di DIY, dan merupakan penelitian kualitatif dengan penggalian data berupa wawancara mendalam. Adapun subjek penelitian adalah warga dan simpatisan Muhammadiyah. Metode analisis yang digunakan adalah analisis isi. Triangulasi dalam penelitian ini digunakan triangulasi metode dan triangulasi sumber.

Adapun hasil penelitiannya adalah, bahwa strategi Komunikasi politik yang dilakukan oleh Tim sukses maupun Afnan sendiri sudah efektif namun masih perlu masifitas dan penajaman. Hal ini terbukti gagasan Afnan yang diusung berupa pendidikan dan kesehatan yang sejak kampanye digelorakan tidak disinggung dan disebut sebagai simbol atau identitas yang mencirikan kekhasan program dan arahan gagasan yang akan diusung Afnan jika terpilih anggota DPD RI.

Kata kunci : strategi komunikasi, elit Muhammadiyah, efektifitas komunikasi 


\begin{abstract}
Muhammadiyah has placed its members as representatives in DPD-RI since 2004. In the 2014 election, Muhammadiyah DIY again propose its cadres as DPD-RI member representatives, but the number of votes obtained tends to decline. This condition makes the Muhammadiyah elite at PWM DIY level to formulate a strategy so that no longer there will be decrease of voice. From the results of the first study, obtained some conclusions; First, in Yogyakarta there is a competition of identity that is the cultural identity of the palace, Muhammadiyah, $\mathrm{NU}$, and others-Muslim, nationalist, and abangan. Second, there is maximization of props. Third, Muhammadiyah highlighted the cultural identity of the use of peci, and used tagline: young and smart, gesang prasojo, makaryo kagem Ngayogyokarto. Fourthly, Muhammadiyah undertook the movement through cultural and structural approaches, for example by sending SMS to all Muhammadiyah leaders throughout Yogyakarta and Muhammadiyah people who work in Muhammadiyah's business charity. Therefore, the study requires continuity to analyze the effectiveness of political communication setrategy by the Muhammadiyah elite DIY to win the cadres of Muhammadiyah when applying M. Afnan Hadikusumo in the election of DPD-RI member in 2014. The purpose of this research is to formulate a better strategy of political communications in the context of member election DPD in the future, considering the coming elections are more competitive.
\end{abstract}

This research will be conducted in DIY, and is a qualitative research with date mining in the form of in-depth interviews. The subject of research is the citizens and sympathizers of Muhammadiyah. The method of analysis used is content analysis. Triangulation in this research used triangulation method and source triangulation.

The results of his research is, that the political communication strategy conducted by the successful team and Afnan itself has been effective but still need the masifitas and sharpening. This is proven by the idea of Afnan that carried in the form of education and health that since the campaign was not mentioned and called as a symbol or identity that characterizes the specificity of the program and the direction of ideas that will be carried Afnan if elected senators of DPD RI.

Keywords: communication strategy, Muhammadiyah elite, communication effectiveness 


\section{PENDAHULUAN}

Dalam proses pemilihan DPDRI di provinsi DIY tahun 2014 yang lalu, Muhammadiyah mengusung M. Afnan Hadikusumo. Ada beberapa masalah yang penting untuk diungkap atas dinamika komunikasi politik internal Muhammadiyah, maupun antara Muhammadiyah dengan organisasi-organisasi yang lain. Mengingat setiap kandidat yang terpilih menjadi anggota DPD RI selama ini adalah tokoh-tokoh masyarakat yang memiliki basis massa yang kongkrit. Sebut saja GKR Hemas merupakan istri Raja Yogyakarta Sri Sultan Hamengkubuwono X yang memiliki basis kultural kerajaan Mataram yang kuat. Sementara Hafidz Asrom merupakan tokoh Nahdlatul Ulama' yang memiliki basis kultural tradisionalis yang kuat, dan Cholid Mahmoed merupakan tokoh agama yang sebelumnya tergabung dengan PKS yang beberapa kali telah menjabat sebagai anggota DPRD, sehingga memiliki popularitas dan basis idiologis PKS yang kuat. Afnan Hadikusumo sendiri merupakan tokoh Muhammadiyah.

Di internal Muhammadiyah sendiri, memang muncul masalah mengenai signifikansi dan urgensi mengusung kadernya menjadi anggota DPD RI. Banyak kader yang mempertanyakan sejauhmana peranan dan manfaat yang bisa diambil dari penempatan wakil di DPD tersebut. Walaupun jumlahnya kecil, ada elit Muhammadiyah yang enggan mendorong dan berkecimpung dalam dunia politik. Selain itu, ada pula elit Muhammadiyah yang melihat efek politik yang bisa memecah-belah keutuhan dan kerukunan umat. Namun di sisi lain banyak kader justru melihat pentingnya wakil Muhammadiyah untuk ikut duduk di DPD RI. Hal ini dimaksudkan agar Muhammadiyah bisa berkiprah memberi kontribusi demi pembangunan bangsa.

Berbagai strategi komunikasi politik tersebut menghasilkan pengaruh tersendiri. Meskipun pada akhirnya M Afnan Hadikusumo berhasil masuk menjadi wakil DPDRI dari DIY, namun strategi komunikasi politik yang dilakukan tersebut masih belum bisa diketahui karena belum pernah diteliti terkait efektifitasnya. Disisi lain ada kecenderungan Muhammadiyah akan meneruskan tradisi mengusung kadernya untuk duduk di DPDRI. Oleh karena itu apa yang telah dilakukan oleh elit politik Muhammadiyah dalam kampanye DPDRI tersebut harus diteliti dengan baik, melalui penelitian yang evaluatif dan komprehensif.

Dari pemaparan diatas, tindak lanjut pengkajian ini penting dilakukan untuk melihat dan memetakan sejauh mana efektifitas komunikasi politik yang dilakukan oleh elit Muhammadiyah di DIY. Dimana pemaknaan efektifitas adalah usaha memilih cara yang tepat agar gambaran dalam benak dan isi kesadaran dari komunikator dapat dimengerti, diterima bahkan dilakukan oleh komunikan ataau khalayak. Untuk keperluan tersebut, melalui kerjasama antara Program Studi Ilmu Komunikasi dan PWM DIY, usulan penelitian tentang efektifitas strategi komunikasi politik elit Muhammadiyah DIY dalam upaya pemenangan calon anggota DPD-RI M Afnan Hadikusumo pada pemilu 2014 ini diajukan. 


\section{TINJAUAN PUSTAKA}

\section{Efektifitas dan Strategi Komunikasi}

Komunikasi yang dilakukan oleh siapapun, akan percuma bila tidak mendapat respon secara efektif. Begitu juga dalam konteks komunikasi elit Muhammadiyah dalam mendorong kader terbaiknya maju dalam pemilu.

Menurut Effendy (2005:130) menjelaskan komunikasi yang efektif harus memenuhi beberapa syarat jika ditinjau dari pesan komunikasi, yaitu.

1. Pada saat keputusan diambil, komunikator harus memastikan bahwa komunikasi yang dilakukan cocok dengan tujuan.

2. Pesan yang disampaikan mudah dimengerti dan dipahami.

3. Secara mental dan fisik, komunikan mampu melaksanakan apa yang diterima.

4. Komunikasi diharapkan sesuai dengan kepentingan kperibadian orang yang diajak komunikasi.

Dalam konteks praktis, Komunikasi Efektif memiliki beberapa prinsip utama. Yaitu, Pertama adalah Respect yaitu sikap hormat dan sikap menghargai terhadap lawan bicara kita. Dalam hal ini Samuel Johnson mengatakan bahwa "there will be no respect without trust, and there is no trust without integrity". Kedua, adalah Empati., yaitu kemampuan untuk menempatkan diri pada situasi atau kondisi yang dihadapi oleh orang lain. Ketiga, Audible. Sebuah pesan hendaknya dapat didengarkan atau dimengerti dengan baik oleh orang lain. Keempat, Clarity. Yaitu kejelasan dari pesan yang disampaikan. Kelima, Humble. Sikap rendah hati adalah unsur sikap untuk membangun rasa menghargai orang lain. (Ilahi, 2010 : 165-166).

Menurut Ardianto bahwa strategi merupakan proses penentuan rencana para puncak pemimpin yang fokus pada tujuan jangka panjang, disertai penyusunan suatu cara atau upaya agar tujuan tersebut dapat dicapai. Sehingga dapat dikatakan bahwa strategi merupakan tindakan yang bersifat incremental yaitu sifat yang senantiasa meningkat dan terus-menerus, serta dilakukan berdasarkan sudut pandang tentang apa yang diharapkan di masa depan. (2008:17).

Sementara itu menurut Andaputra dalam Ruslan, (1998:106). dikemukakan bahwa strategi adalah bagian terpadu dari suatu rencana (plan), sedangkan rencana merupakan produk dari suatu perencanaan (planning), yang pada akhirnya perencanaan merupakan suatu fungsi dasar dari proses menajemen.

Anwar Arifin (1994:10) mengemukakan strategi komunikasi agak berbeda dengan pakar yang lain, yaitu sebuah keputusan kondisional tentang tindakan yang akan dijalankan guna mencapai tujuan. Oleh karena itu, strategi komunikasi berarti memperhitungkan kondisi dan situasi dalam menyampaikan pesan yang di dalamnya terkait ruang dan waktu, yang dihadapi dan yang akan dihadapi, untuk mencapai efektivitas. 
Menurut beberapa pakar, ada dua bentuk strategi komunikasi politik, yaitu: Pertama, strategi komunikasi politik yang cenderung mengambil atau membentuk posisi horizontal. Dalam hal ini posisi antara komunikator politik dan komunikan (publik, masyarakat) relatif seimbang yaitu saling memberi dan menerima, sehingga terjadi diskursus dan dialektika, bentuk strategi semacam ini merupakan refleksi nilai-nilai demokratis. Kedua, strategi komunikasi politik yang cenderung membentuk pola linier. Arus komunikasi satu arah cenderung vertikal (top down). Hal ini merefleksikan nilainilai budaya yang kolot dan feodalistik sehingga lahir model kepemimpinan yang cenderung totaliter atau otoriter (Zein, 2008:109).

\section{Komunikasi Politik}

Menurut Lynda Lee Kaid (2004:xiii) komunikasi politik adalah "role of communication in the political process" yaitu penggunaan (ilmu) komunikasi dalam proses politik.

Doris Graber mengkritik terkait komunikasi politik karena dianggap hanya membincangkan kekuasaan. Menurutnya sebagaimana dikutip oleh Hafid Cengara, (Cengara, 2011:30) bahwa komunikasi politik bukan hanya retorika, tetapi mencakup simbol-simbol bahasa, tindakan, bahasa tubuh. Sehingga dapat dirumuskan bahwa komunikasi politik sebagai sebuah proses pengoperan simbol-simbol komunikasi yang berisi pesan politik dari seorang atu sekelompok orang kepada orang lain untuk mempengaruhi sikap yang menjadi target politik.

Dapat disimpulkan bahwa komunikasi politik adalah komunikasi yang bercirikan politik yang terjadi di dalam sebuah sistem politik. Komunikasi politik dapat berbentuk penyampaian pesan-pesan yang berdampak politik dari penguasa politik kepada rakyat banyak ataupun penyampaian dukungan atau tuntutan oleh rakyat bagi penguasa politik. McNair (dalam Canggara, 2011:39) menjelaskan lebih jauh bahwa komunikasi politik memiliki lima fungsi dasar dalam melaksanakan strategi komunikasi, yakni sebagai berikut; pertama, Strategi komunikasi politik diharapkan mampu memberikan informasi kepada masyarakat apa yang terjadi disekitarnya. Kedua, Mendidik masyarakat terhadap arti dan signifikansi fakta politik yang ada. Ketiga, Menyediakan institusi politik yang baik dengan platform untuk menampung masalah-masalah politik sehingga bisa menjadi wacana dalam membentuk opini publik, dan mengembalikan hasil opini itu kepada masyarakat. Keempat, Membuat publikasi yang ditujukan kepada pemerintah dan lembaga-lembaga politik. Kelima, Dalam masyarakat yang demokratis, media politik berfungsi sebagai saluran advokasi dan penyeimbang yang bisa membantu agar kebijakan dan program-program lembaga politik dapat disalurkan kepada masyarakat.

\section{Elit muhammadiyah}

Masyarakat memiliki orang-orang yang mempunyai peranan menonjol dan berpengaruh. Mereka inilah yang disebut elit (Keller, 1995:31). Istilah elit sebenarnya berasal dari kata latin eligere yang berarti "memilih." Pada abad k-18, kata tersebut telah meluas di Perancis dan berangsur-angsur menyebar ke Eropa. Kaum elit sendiri merupakan orang- 
orang yang tergolong minoritas, di mana mereka sangat efektif dan bertanggungjawab. Efektif dalam melihat fonomena masyarakat dan menitikberatkan kepentingan serta perhatian kepada orang lain dimana tempat golongan elit ini memberikan tanggapannya. (T.B. Bottomore, 2006:1-2).

Menurut T. B. Bottomore (2006:1,) kata 'elite' awalnya hanya digunakan untuk menggambarkan barang-barang tertentu yang dianggap memiliki kualitas terbaik. Kemudian makna kata tersebut menjadi lebih luas dan mengarah pada pada kelas-kelas sosial yang memiliki keunggulan, seperti korps militer kelas satu dan para kaum bangsawan.

Ditengah masyarakat modern tidak terlepas dari golongan elit dalam masyarakat. Asumsinya jika yang menjalankan pemerintahan adalah rakyat maka sesuatu yang keliru, karena sesunggunya yang menjalankan kebijakan adalah para elit. (Jarry dalam Jurdi, 2004:19-20). Syarifuddin Jurdi, menambahkan yang disebut elit adalah sekelompok kecil dalam masyarakat yang memegang posisi dan peranan penting. Dengan kata lain bahwa elit adalah segolongan kecil yang memperoleh sebagian besar dari nilai, status dan pengaruh serta previlage dalam masyarakat, (Jurdi, 2004:21).

Tokoh sosiologi Mosca memberi ilustrasi bahwa di masyarakat mana saja, baik masyarakat yang masih baru tumbuh hingga yang sudah mampu membangun peradaban yang lebih mapan, yang berkembang menjadi masyarakat yang lebih maju dan powerful, di dalamnya terdapat dua klas masyarakat yaitu klas yang menguasai dan yang dikuasai. Sementara itu, kelas yang kedua jumlahnya jauh lebih besar, secara langsung dikuasai dan dikendalikan oleh kelas yang pertama, yang dalam hal ini sekarang menjadi kurang lebih biasa, dan dijalankan dengan cara yang kurang lebih arbitrair dan dengan kekerasan, intimidasi dan propaganda, (Zainudin Maliki, 2010:xi).

Menurut stratifikasi politik yang disusun Pareto, mayarakat terdiri atas dua kelas yakni: kelas pertama adalah lapisan atas, yaitu terbagi atas elite yang memerintah (governing elite) dan elite yang tidak memerintah (non governing elite). Kelas kedua adalah lapisan masyarakat yang lebih rendah, yaitu non elite, dalam hal ini adalah massa. Menurut Robert D. Putnam, (Mas'oed dan Mc Andrews, 1995:91-94) ada tiga cara untuk mengidentifikasi hal tersebut, yakni dengan analisa posisi, reputasi dan keputusan.

Pada masyarakat modern, sebagaimana perspektif Suzanne Keller dapat dijadikan sebagai asumsi mengenai elite. Dia melihat bahwa pada masyarakat modern dimensi kekuasaan tidak hanya satu, melainkan beberapa dimensi. Dalam setiap kegiatan sosial kemasyarakatan, di dalam maupun di luar pemerintahan terdapat satu atau lebih individu yang menonjol karena keahlian atau keterampilannya dalam bidang tertentu. Disinilah Keller menyebutnya sebagai "elite strategis", misalnya elite politik, suku, ekonomi, militer, pengetahuan, pendidikan, falsafat, agama, kesenian dan kesusastraan. Bila dilihat secara kolektif, mereka merupakan kelas yang memiliki kuasa dalam 
masyarakat, dimana perkataanya didengar bahkan terkadang diikuti. (Miriam Budiardjo, 1984:22-23).

Dari pemaparan diatas, konsep elit Muhammadiyah DIY dalam hal ini adalah para pengurus 13 PWM DIY, ketua semua organisasi otonom ('Aisyiyah, PM, NA, IMM, IPM, HW dan TS). Kemudian ketua PDM di lima kabupaten dan tentunya pengurus LHKP PWM DIY sebagai pemegang mandat serta setruktur tim pemenangan.

\section{METODE PENELITIAN}

\section{Pendekatan}

Dalam penelitian ini menggunakan pendekatan kualitatif. Dikarenakan dalam penelitian ini berusaha mengeksplorasi dan memahami makna yang dianggap berasal dari masalah sosial, (Creswell, 2010:4-5). Strategi penelitian dilakukan secara empiris, yang menyelidiki sebuah fenomena dalam kehidupan nyata dengan memanfaatkan berbagai sumber bukti, untuk menjawab pertanyaan-pertanyaan "bagaimana dan mengapa". Hal ini dikarenakan, studi dalam situasi ilmiah (naturalistic inquiry), mengunakan teknik analisis deduktif, kontak langsung periset dengan obyek, prespektifnya holistik dan dinamis, serta periset sebagai instrument kunci. Yaitu peneliti menetapkan kaidahkaidah penelitian ilmiah dengan obyektif serta bebas dari interfensi, (Salim, 2006:8-10).

\section{Teknik Pengumpulan Data dan Triangulasi Penelitian}

Data dari informan digali dengan teknik wawancara mendalam. Sehingga memerlukan guideline dalam menyampaikan pertanyaan. Data tentang dokumen digali dengan analisis isi. Triangulasi dalam penelitian ini digunakan triangulasi metode dan triangulasi sumber.

\section{HASIL DAN PEMBAHASAN}

\section{Strategi komunikasi Politik}

Maksimalisasi alat peraga

Dalam mensosialisasikan Afnan Hadikusumo, tim mencetak berbagai macam atribut kampanye. Diantaranya adalah:

- Stiker

- Baliho

- Bilboard

- Pin

- Kertas suara

- Kalender

- Liflet

- Rontek

- Spanduk 
- Buku

- Kartu nama

- Branding mobil

- Buku panduan saksi

\section{Membuat Slogan}

Beberapa penekanan untuk mempermudah sosialisasi maka menggunakan kata-kata yang dijadikan trendmark, seperti "makaryo kagem Ngayogyakarto", "korsa", "gesang prasojo", "muda dan cerdas", dan "Muhammadiyah gerakanku, AMM kebangganku, Afnan Hadikusumo DPD-ku". Pesan-pesan lingual tersebut menegaskan bahwa Afnan mempunyai semangat kekitaan, kecintaan terhadap perhimpunan/ organisasi dalam hal ini Muhammadiyah dan sebagai bagian dari masyarakat Yogyakarta, serta menunjukan pengabdian dirinya kepada daerah sendiri yaitu Yogyakarta.

\section{Identitas Batik}

Penggunaan baju batik oleh Afnan berikut dengan tim suksesnya. Baju batik yang dikenakan oleh Afnan berikut dengan tim suksesnya merupakan upaya menunjukkan diri sebagai kandidat wakil rakyat yang mencintai produk dalam negeri dan mampu melestarikan salah satu kebudayaan negeri sendiri. Secara tidak langsung upaya ini dilakukan oleh Afnan dalam rangka pencitraan akan kecintaannya terhadap batik. Selain itu yang menjadi poin penting dalam pemilihan pakaian batik oleh Afnan dan kelompok merupakan upaya pembeda dirinya dengan kelompok/calon wakil rakyat yang lainnya. Sehingga calon pemilih lebih mudah mengingat, jika yang menggunakan batik tersebut adalag Afnan.

\section{Mobilisasi Massa}

Gerakan kultural dan struktural dilakukan untuk memaksimalkan strategi komunikasi. Gerakan kultural dilakukan dengan pengerahan tokoh Muhammadiyah untuk mengisi pengajian, tabligh akbar, jalan sehat, bakti sosial dsb. Adapun secara struktural dilakukan dengan konsolidasi dan rapat-rapat pemenangan. Selain hal tersebut juga dilakukan dengan mengirim sms ke seluruh pimpinan Muhammadiyah se DIY dan juga warga Muhammadiyah yang bekerja di amal usaha Muhammadiyah.

Memanfaatkan ortom dan pengajian untik mensosialisasikan $\mathrm{AH}$ bagi beberapa pihak memang menganggapnya agak kurang tepat. Namun dalam dunia poitik, mobilisasi massa seperti ini adalah hal yang lumrah dilakukan oleh para pimpinan politik, pejabat publik, dan pejabat elit lainnya. Di berbagai negara yang memakai prinsip demokrasi, politik mobilisasi adalah salah satu sarana yang jitu untuk dipakai guna mendapatkan dukungan dan memberikan persuasif penuh pada para simpatisan atau pendukungnya, termasuk di dalamnya dalm hal ajakan atau sosialisasi sebuah kebijakan 


\section{SMS Center}

Selain mobilisasi dan tatap muka dengan warga Muhammadiyah, tim juga menyiapkan perangkat sms center. Tim IT yang digawangi anak-anak muda mengentri nomor kontak pengurus dan juga warga Muhammadiyah yang bekerja di amal usaha Muhammadiyah. Terkumpul kurang lebih 12.000 nomor handphon. Seminggu sekali mereka mendapat sms broadcas dari tim. Dan durasi semakin sering ketika menjelang pemilihan. Adapun konten yang disampaikan cenderung umum dan bernuansa ibadah. Artinya mengajak kebaikan, tidak langsung menukik permintaan untuk mendukung dan memilih Afnan. Dari sms tersebut banyak ragam respons. Ada yang mendukung, ada yang menanyakan urgensi DPDRI bahkan ada yang menolak baik secara halus maupun terbuka. Namun kebanyakan tanpa respon.

\section{Pemanfaatan Sosial Media}

Laman facebook tersebut dioprasikan oleh tim guna mensosialisasikan profile Afnan Hadikusumo. Didalamnya dituliskan status-status bernada dakwah. Hal ini dilakukan tidak saja mengenalkan Afnan sebagai calon DPDRI melainkan juga sebagai sarana dakwah.

Selain facebook, Afnan bersama tim juga membuat weblog. Weblog tersebut diberi nama relawan 1912 dan relawan Afnan. Tujuan dan fungsinya sama dengan facebook, yaitu untuk mensosialisasikan profil, program dan visi-misi Afnan Hadikusumo yang mencalonkan diri menjadi anggota DPDRI.

\section{Mengawal Suara Lewat Saksi dan Relawan}

Terakhir, tim Afnan Hadikusumo membentuk relawan sebagai saksi saat pencoblosan dan perhitungan suara. Saksi yang diterjunkan berjumlah 8.500 orang. Saksi tersebut akan ditempatkan di TPS, kemudian juga untuk mengawal rekapitulasi tingkat desa, kecamatan, kabupaten dan terakhir disahkan di KPUD Provinsi. Hal ini dilakukan untuk mengawal suara dari tempat pencoblosan sampai di KPU ketika ditetapkan. Harian Kedaulatan Rakyat online memberitakan penerjunan relawan sebagaimana gambar dibawah ini.

Gerakan relawan sebagai saksi dibekali dengan pelatihan dan juga buku panduan. Pelatihan yang dilakukan berupa advokasi dan juga prosedur serta tatacara maupun aturan mengenai saksi. Selain pelatihan para relawan juga dibekali sebuah buku panduan saksi

\section{Citra yang Ditanamkan}

Latar belakang budaya merupakan menjadi tonggak penting dalam mempengaruhi citra seorang kandidat. Apalagi Indonesia khsusnya DIY, masyarakat menyukai image tokoh yang bersahaja, sederhana dan mau mengerti hati nurani rakyatnya. Image berpakaian juga penting untuk ditelaah lebih lanjut, misalnya saja memakai batik atau pakaian tidak resmi di sela-sela kegiatan. 
Secara personal Afnan ditampilkan sebagai figur sederhana, muda, cerdas, dan amanah. Status Afnan sebagai kader Muhammadiyah aktif berusaha ditampilkan tidak ekslusif hanya untuk golongan Muhammadiya saja, melainkan bersifat inklusif yang mampu menampung aspirasi dari warga DIY yang bukan hanya anggota maupun simpatisan Muhammadiyah.

Pemaparan tokoh-tokoh elit mensiratkan bahwa pencitraan Afnan sebagai kader Muhammadiyah sangat penting. Hal ini ditopang oleh gerakan amar ma'ruf nahi mungkar yang selama ini dilakukan oleh Muhammadiyah. Artinya Afnan dilihat sebagai sosok yang mampu melaksanakan amar ma'ruf nahi mungkar tersebut.

\section{Branding di Sosial Media}

Untuk sosialisasi di ranah publik, Afnan bersama tim membentuk media sosial. Di antaranya adalah facebook dengan nama Relawan Afnan dan Gerakan Satu Juta Relawan Afnan. Hal ini tampak seperti gambar dibawah ini.

Gambar 1.

Halaman Facebook Relawan Afnan

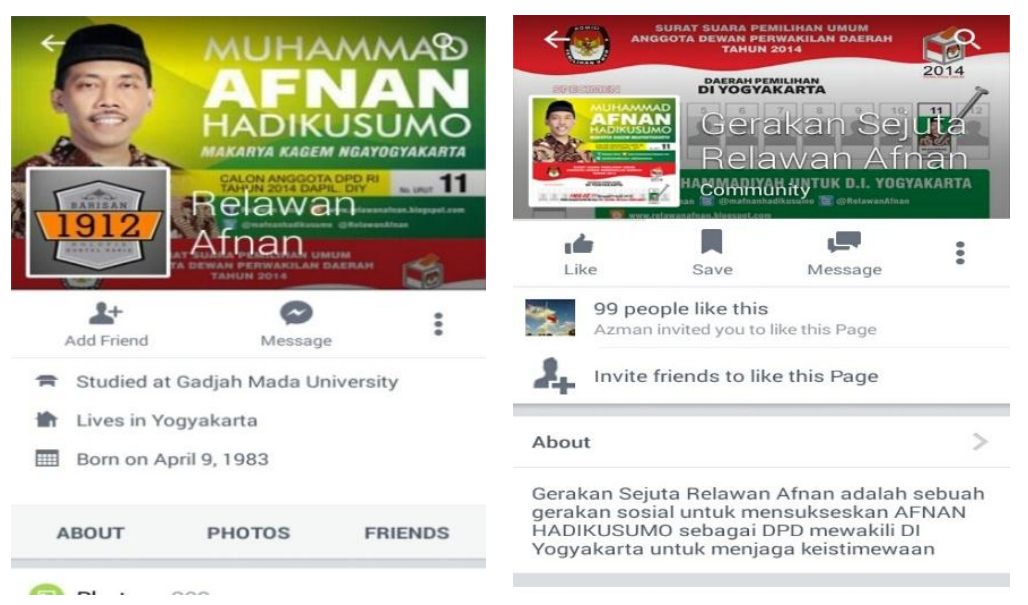

Gambar 2.

Laman Web/Blog Relawan Afnan
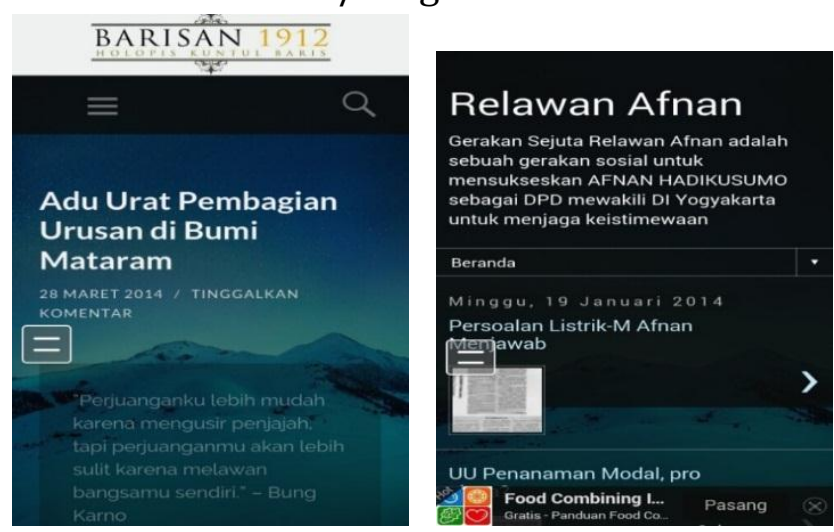
Dalam weblog diposting berbagai macam gagasan Afnan, termasuk pendidikan, kesehatan, listrik sampai perpolitikan di bumi Mataram atau DIY. Terakhir, tim Afnan Hadikusumo membentuk relawan sebagai saksi saat pencoblosan dan perhitungan suara. Saksi yang diterjunkan berjumlah 8.500 orang. Saksi tersebut ditempatkan di TPS, dan mengawal rekapitulasi tingkat desa, kecamatan, kabupaten hingga disahkan di KPUD Provinsi. Strategi ini dilakukan untuk mengawal suara dari tempat pencoblosan sampai di KPU saat ditetapkan. Harian Kedaulatan Rakyat online memberitakan penerjunan relawan tersebut.

\section{Pembahasan Efektifitas Strategi Komunikasi}

Sebelum diulas lebih mendalam terkait hasil wawancara dengan masyarakat gressroot terkait sejauh mana efektifitas komunikasi politik maka terlebih dahulu akan diuraikan gambaran peta politik. Peta politik ini penting untuk meneropong sebaran dan karakteristik warga yang memiliki hak pilih. Peta politik warga DIY dapat dipetakan sebagai berikut

Warga nasionalis. Jumlah warga DIY yang nasionalis merupakan mayoritas. Ini terbukti dari menangnya PD pada pemilu 2009 dan PDIP pada 2012. Basis nasionalis ini dalam pemilihan DPD RI terserap di suara GKR Hemas yang jumlah suarannya mencapai 1 juta lebih. Sisanya terpecah dalam kantong-kantong suara lain yang memiliki background nasionalis. Seperti Bambang dari Gunung Kidul, Ismarindayanti yang merupakan istri dari menpora Roy Suryo, Warga Muhammadiyah. Warga Muhammadiyah terfokus suaranya pada Afnan Hadikusumo. Karena Muhammadiyah hanya mengusung satu nama tersebut. Berbeda dengan tahun 2009 yang terpecah. Dimana tahun 2009 ada calon yang bernama Sugito, M.Si. Sugito, M.Si merupakan anggota pimpinan wilayah Muhammadiyah DIY. Selain itu juga mantan pengurus PGRI dan kepala dinas pendidikan DIY. Sehingga suara yang diraih Sugito juga lumayan, yaitu mencapai 50.000 suara lebih. Jika suara tersebut disatukan dengan suara Afnan Hadikusumo tahun 2009 maka Afnan akan menempati posisi urutan nomor 2 setelah GKR Hemas. Namun tahun 2014 walaupun suara Muhammadiyah tidak mengalami perpecahan namun suara Afnan ternyata tidak maksimal. Tentu ini pasti ada problem yang perlu diungkap.

Warga NU, suaranya terpecah karena banyak kadernya yang maju DPD RI. diantaranya Fairuz Ahmad ketua GP Ansor DIY, Abdul Muhaimin pengasuh pondok Nurul Ummah, Taufiqurrahman ketua PC NU Kota Yogya dan Hafid Asrom. Namun dari kalangan NU yang terpilih adalah Hafidz Asrom. Hafidz Asrom merupakan anggota DPDRI incumbent dan juga pernah mencalonkan diri sebagai bupati Sleman namun kalah. Sehingga tokoh ini sudah tidak asing lagi di DIY.

Warga non muslim. Warga DIY dengan identitas keagamaan selain Islam juga mulai merambah dunia politik. Mereka mulai mengencangkan ikat pinggang untuk mengusung calon DPD RI. Warga non Muslim tersebut khususnya agama Katolik. Yang mengusung 
Fidelis. Sangat mungkin dipemilihan yang akan datang, mereka bisa mendapatkan suara yang signifikan.

Dari hasil wawancara dengan para pimpinan Cabang, Ranting serta warga Muhammadiyah dengan komponen utama pertanyaan mengenai representasi, konerja Afnan sebelumnya, simbol, media dan efektifitas komunikasi politik, dapat dijabarkan sebagai berikut:

Dasar pertimbangan Afnan Hadikusumo sebagai representasi Muhammadiyah untuk maju DPD RI

Menurut Fauzan salahseorang pemuda yang menjadi anggota PCM Imogiri, Bantul, mengatakan, "Afnan Hadikusumo bisa menjadi representasi Muhammadiyah karena dapat mentransformasikan gagasan Muhammadiyah untuk kemajuan bangsa". Hal ini menunjukan bahwa Afnan Hadikusumo dapat dijadikan sebagai representasi Muhammadiyah atau sosoknya bisa mewakili Muhammadiyah karena ide-ide yang diusung nya merupakan perwujudan dengan kepentingan Muhammadiyah. Memang dalam kampanye untuk maju DPDRI keduakalinya Afnan banyak mengusung tentang pentingnya kesehatan dan pendidikan. Kesehatan dan pendidikan merupakan lahan dakwah Muhammadiyah yang selama ini telah massif dan merupakan program pokok Muhammadiyah. Mengingat Muhammadiyah memiliki Amal Usaha dibidang pendidikan dan kesehatan yang jumlahnya mencapai ribuan.

Senada dengan hal tersebut di atas, Hatib R salah seorang aktifis muda Muhammadiyah dari PCM Berbah, Sleman mengatakan "Afnan adalah kader Muhammadiyah yang sudah berpengalaman dan dapat dipercaya". Kunci yang muncul adalah Afnan berpengalaman dan dipercaya. Ini merupakan kalimat yang muncul dari warga terkait dengan karakter dan treckrecord Afnan Hadikusumo sebelumnya. Dimana Afnan pernah satu periode menjadi anggita DPDR Provinsi DIY dan satu periode menjabat anggota DPDRI. Hatib selaku warga memiliki pandangan jika antara perkataan dan perbuatan Afnan selama ini segaris lurus. Artinya memiliki komitmen dan juga menjalankan janji-janjinya selama kampanye.

\section{Kinerja Afnan periode sebelumnya (2009-2014)}

Sebuah indikator sederhana untuk mengetahui sejaumana kinerja seorang politisi adalah dengan melihat sepak terjangnya selama ini. Dan yang paling falid adalah menelisik kinerja periode sebelumnya jika dia telah menjadi pejabat publik. Akan lebih mudah jika jabatan itu sama. Kebetulan Afnan hadikusumo ketika maju mencalinkan diri menjadi calin anggota DPDRI tahun 2014, lima tahun sebelumnya yaitu periode 2009-2014 telah manjadi anggota DPDRI. Tentu ini lebih mudah untuk memetakan kinerjanya oleh masyarakat.

Iman sumarlan dari PCM Setolo mengatakan "kinerja Afnan selama ini memuaskan dengan indikator pergaulan sehari-hari". Hal ini didasarkan atas kinerja Afnan 
Hadikusumo selama satu periode atau lima tahun menjadi anggota DPDRI. Kinerja Afnan Hadikusumo pada tahun 2009-2014 sangat membekas di benak warga Muhammadiyah. Sehingga itu dijadikan dasar untuk menentukan dan memilih kembali Afnan Hadikusumo sebagai anggota DPDRI periode 2014-2019.

Sementara menurut Hamam, "Afnan mampu membawa Muhammadiyah dalam konstelasi politik nasional". Hal ini terlihat dengan berbagai program Afnan dalam membantu Muhammadiyah. Misalkan semua cabang Muhammadiyah diberi sumbangan dana untuk melakukan Muscab, kemudian PDM dibantu dana untuk melakukan Musyda. Selain itu banya amal usaha yang meminta sumbangan. Entah itu pembangunan sekolah, masjid maupun sekedar sumbagngan dalam kegiatan. Disisi lain banyak warga masyarakat yang di bantu walalupun tidak berafiliasi pada Muhammadiyah.

\section{Simbol dan politik identitas yang ditonjolkan}

Dalam marketing politik, salah satu komponen penting adalah simbol-simbol yang dimunculkan untuk menarik simpati atau dijadikan ikon. Semisal Jokowi dengan gaya blusukannya, Prabowo dengan menunjukan ketegasan dengan didukung oleh pakaian. Songkok dan jubah sebagai simbol Islam atau blangkon sebagai simbol orang Jawa. Selain atribut yang melekat ada juga karakter yang dimunculkan untuk menunjukan simbolsimbol tersebut.

Begitu juga dengan Afnan Hadikusumo. Ada beberapa komponen yang ditonjolkan baik dari segi performance atau penampilan maupun sikap. Dari segi sikap, menurut Fauzan, "kesederhanaannya dan idealismenya dalam membentuk masyarakat yang pluralis dan progresif". Afnan dianggap memiliki sikap dan idealisme untuk mewujudkan dan melaksanakan keinginan atau aspirasi warga DIY dan warga Muhammadiyah khususnya. Adapun menurut Syaifullah, tokoh masyarakat dari Sapen, Sleman, "DPD RI dari Muhammadiyah menonjolkan islam berkemajuan serta mengusung tema-tema pemberdayaan masyarakat". Kata Islam berkemajuan merupakan slogan Muhammadiyah, dengan slogan tersebut diharapkan warga Muhammadiyah akan dengan mudah mengenali Afnan sebagai calon DPD yang menjadi representasi Muhammadiyah.

Sedangkan menurut Fauzi Islah pengurus DPD IMM dan warga Sleman melihat Afnan menonjolkan slogan "bersih, Muda”. Hal ini diharapkan menjadi ciri khas untuk menarik simpati kaum muda. Dengan slogan tersebut sosok Afnan dikenalkan dan diharapkan mampu menjaring suara karena kecerdasannya.

Hatib R, menambahkan "isu negatif ditangkal dengan intensitas kunjungan Afnan ke basis-basis Muhammadiyah dan setiap isu negatif harus di tangkal". Dari sini bisa dilihat jika isu negatif banyak muncul untuk character assasination. Maka hal tersebut harus ditangkal. Hal ini diperkuat oleh hasil wawancara dengan Iman sumarlan. Dia 
mengatakan "kalau ada isu negatif yang dihembuskan maka dibiarkan saja karena dalam politik marketing hater sering dihadirkan".

\section{Media yang diterima saat saat kampanye Afnan Hadikusumo}

Saat dunia teknologi informasi berkembang dan terus berubah secara dinamis mengikuti perkembangan zaman, maka teknik kampanye atau publikasi juga demikian. Maraknya media sosial dan branding politik mendorong politisi untuk memanfaatkan media. Banyak politisi memasang baliho, spanduk, stiker, branding mobil, kalender, leaflet, kaos bahkan kartu nama yang dijadikan sebagai alat untuk mengkampanyekan diri. Begitu juga dengan Afnan Hadikusumo. Namun menurut hasil wawancara ternyata media itu semua tidak efektif untuk mendongkrak elektabilitas. Jika sekedar mendongkrak popularitas mungkin ada benarnya.

Menurut warga DIY, Syaifullah dari Sapen media online dan media cetak perlu di massifkan karena mampu merubah cara pandang terhadap Muhammadiyah. Adapun menurut Qomarudin agak lebih luas yaitu benner. Sedangkan warga Muhammadiyah Hadi Pranoto dari Kalasan, Andi Priana dari Kulonprogo melihat media sosial sangat efektif jika digunakan sebagai media kampanye untuk Afnan Hadikusumo. Dari hasil wawancara beberapa orang diatas ternyata masyarakat atau warga DIY mengenal Afnan bersumber dari beberapa media. Ini menunjukan jika memeng penggunaan media perlu dimaksimalkan dan tidak hanya fokus satu media saja.

Namun Fauzan menjelaskan, media yang mudah diterima sebagai sarana kampanye adalah, "kajian-kajian Muhammadiyah dan media sosial". Hal ini ditegaskan oleh Hatib R. "relasi harus dibangun secara kontinue agar menjadi media darling". Artinya bahwa pertemuan langsung atau tatap muka dengan masyarakat sangat penting dan akan membekas. Hal ini sejalan dengan teori bahwa tatap muka akan memperkuat ikatan psikologi. Cara yang digunakan bisa bermacam-macam. Misalnya pengajian, bakti sosial, jalan sehat ataupun sekedar kunjungan. Kedekatan akan terbangun dengan interaksi langsung, bercakap-cakap ataupun diskusi. Disisi lain Hatib mengatakan untuk membangun komunikasi secara kontinyu agar kedekatan secara emosional semakin kuat. Hal ini untuk menutup kemungkinan masuknya kompetitor. Karena lawan politik juga mempunyai hasrat untuk dipilih dan juga membangun komunikasi. Jika komunikasi tidak intens maka kompetitor politik bisa merebut basisi suara.

\section{Efektifitas strategi komunikasi politik Tim Sukses Afnan Hadikusumo}

Untuk menimbang sejauh mana efektifitas komunikasi politik, bisa dilihat dari penjelasan-penjelasan dari warga atau konstituen. Diantaranya, Fauzan dari Bantul mengungkapkan "Komunikasi politik yang dilakukan cukup efektif karena menggunakan media pengajian Muhammadiyah dan Aisyiyah". Sesuai dengan pernyataan warga Muhammadiyah yang lain seperti Hatib, maka tatap muka dengan mengemas dalam bentuk pengajian merupakan sarana kampanye yang efektif. Hal ini juga di sampaikan 
Hamam dari PCM Depok. Buktinya efektif adalah Afnan kembali terpilih DPD RI periode 2014-2019.

Adapun menurut warga Muhammadiyah dari Sapen, pak Arif "lebih efektif dengan terjun langsung ke masyarakat sehingga tidak hanya mengumbar janji saja". Agak berbeda disampaikan oleh warga di Wirobrajan Yogyakarta. Yusuf anggoro mengatakan "semua media komunikasi perlu dikerahkan terutama media persyarikatan Muhammadiyah". Hal ini menjadikan indikasi bahwa media-media yang dimiliki oleh Muhammadiyah, yang terkenal seperti majalah SM, web Muhammadiyah, majalah Suara Aisyiyah dan mediamedia lokal lainnya belum maksimal dalam mengkampanyekan calon anggota yang maju DPD RI.

Adapun menurut Fauzi Islah dari Mrican Sleman, "jangan hanya mengandalkan suara dari warga Muhammadiyah, tetapi diluar Muhammadiyah perlu dijadikan bidikan". Fauzan melihat selama ini tim sukses hanya berkampanye dikalangan warga Muhammadiyah, padahal warga yang nasionalis dan lainya masih banyak dan juga berpotensi mendulang suara.

Pandangan Hatib R melihat efektifitas komunikasi politik Afnan beserta tim sukses selama ini, "ada yang efektif dan ada yang tidak. Yang efektif melalui jalur struktur Muhammadiyah, yang tidak efektif adalah kampanye untuk orang diluar Muhammadiyah. Hambatannya, maka perlu mengefektifkan komunikasi dengan internal Muhammadiyah mengingat Afnan berasal dari Muhammadiyah".tidak bisa dipungkiri suara Afnan selama ini berbasis Muhammadiyah, maka perlu dijaga dan dirawat komunikasinya. Namun yang agak berat adalah komunikasi dengan orang luar Muhammadiyah, memperkenalkannya dan berharap menjatuhkan pilihan. Ini yang dirasa oleh warga Muhammadiyah belum di garap secara maksimal.

\section{SIMPULAN}

Dari penjabaran dalam hasil analisis tersebut dapat ditarik kesimpulan bahwa:

Strategi Komunikasi politik yang dilakukan oleh Tim sukses maupun Afnan sendiri sudah efektif namun masih perlu masifitas dan penajaman. Hal ini terbukti gagasan Afnan yang diusung berupa pendidikan dan kesehatan yang sejak kampanye digelorakan tidak disinggung dan disebut sebagai simbol atau identitas yang mencirikan kekhasan program dan arahan gagasan yang akan diusung Afnan jika terpilih anggota DPD RI.

Metode kampanye yang paling digemari adalah tatap muka. Baik itu silaturahmi akbar atau pengajian. Hal ini dinyatakan oleh konstituen karena dianggap terasa lebih dekat dan merakyat. Sehingga kedekatan personal bisa terbentuk dengan komunikasi dua arah dan terbangun dialog yang konstruktif. Lebih lanjut akan diketahui visi misi dan program jika terpilih. Selain itu juga lebih mudah untuk menagih janji kedepannya. 
Adapun saran yang diberikan kedepan adalah hendaknya calon yang diusung oleh Muhammadiyah disiapkan jauh-jauh hari sebelumnya, sehingga bisa membangun popularitas. Kemudian calon Muhammadiyah hendaknya memiliki branding image yang bisa dijual kepada masyarakat khususnya massa diluar Muhammadiyah. Yang terakhir adalah membangun kiomunikasi dengan tatap muka perlu ditekankan baik itu melalui pertemuan atau pengajian. Hal ini untuk membangun kedekatan personal calon dengan masyarakat.

\section{DAFTAR PUSTAKA}

Ardianto, Elvinaro.2008. Filsafat Ilmu komunikasi.Bandung. Bandung : Simbiosa Rekatama Media

Arifin, Anwar. 1994. Strategi Komunikasi, Sebuah Pengantar Ringkas. Bandung : CV. ARMICO.

Bottomore, T. B. 2006. Elite dan Masyarakat. Terj. Abdul Haris dan Syaid Umar, Jakarta: Akbar Tandjung Institute.

Budiardjo, Miriam. 1984. “Konsep Kekuasaan: Tinjauan Kepustakaan". Jakarta: Pustaka Sinar Harapan.

Cengara, Hafied. 2011. Komunikasi Politik : Konsep, Teori dan Strategi. Jakarta : Raja Grafindo.

Creswell, John, W. 2010. Research Design : Pendekatan Kualitatif, Kuantitatif dan Mixed. Edisi ketiga. Terj. Ahmad Fawaid. Yogyakarta : Pustaka Pelajar.

Effendi, Onong Uchjana. 2005. Ilmu Komunikasi; Teori dan Praktek. Bandung: PT. Remaja Rosdakarya.

Ilaihi, Wahyu. M.A. 2010, Komunikasi Dakwah, PT. Remaja Rosdakarya, Bandung, Cet. 1

Jurdi, Syarifuddin. 2004. Elite Muhammadiyah Dan Kekuasaan Politik: Studi Tentang Tingkah Laku Politik Elite Lokal Muhammadiyah Sesudah Orde Baru. Yogyakarta : Gadjah Mada University Press.

Kaid, Lynda Lee (ed). 2004. Handbook of : Political Communication Research. New Jersey : Laurence Erlbaum Associates

Keller, Suzanne, 1995. Penguasa dan Kelompok Elit. Jakarta :Raja Grafindo Persada. Maliki, Zainudin. 2010. Sosiologi Politik, Yogyakarta: Gadjah Mada University Press. 
Mas'oed, Mohtar dan Mc Andrews, Collin (Eds.). 1995 Perbandingan Sistem Politik, Yogyakarta: Gadjah Mada University Press.

Salim, Agus. 2006. Teori dan Paradigma Penelitian Sosial. Yogyakarta : Tiara Wacana.

Zein, Abdullah. 2008. Strategi komunikasi Politik dan Penerapannya. Bandung : Simbiosa. 
EFEKTIFITAS STRATEGI KOMUNIKASI POLITIK ELIT MUHAMMADIYAH

DIY DALAM PEMENANGAN PEMILU DPD-RI TAHUN 2014

Anang Masduki, Rendra Widyatama 